\title{
RESECTION AND REGENERATION- A HOPE FOR THE HOPELESS
}

\section{Periodontology}

Dr. Apeksha $\quad$ Post graduate, Department of Periodontics, V. S. Dental College and hospital, K. R. Road, Annigeri B.* V. V. Puram, Bangalore-560004.*Corresponding Author

\section{Dr. Rajiv Nidasale Professor, Department of Periodontics, V. S. Dental College and hospital, K. R. Road, V.} Puttaswamaiah V.Puram, Bangalore-560004.

Dr. Avinash Janaki Professor, Department of Periodontics, V. S. Dental College and hospital, K. R. Road, V. Lingaraju

\section{ABSTRACT}

Preservation of tooth structure has always been the prime aim of dental practice. Teeth with advanced periodontal disease in multirooted teeth often pose a significant challenge to the clinician, complicating the treatment plan and compromising long term prognosis. The outcome of the treatment is determined by proper case selection and surgical, endodontic and prosthetic parameters. Resective and regenerative osseous procedures are often employed to help preserve the tooth structure, alveolar bone involving the retained root of multirooted teeth and are cost effective over the other treatment options like ridge preservation/augmentation followed by implant placement. This case series describes application of resective and regenerative techniques for molars with extensive combined periodontal-endodontic disease.

\section{KEYWORDS}

Advanced periodontal disease, Hemisection, Resection, Regeneration

\section{INTRODUCTION}

Fascination of saving natural teeth than having a prosthesis, led to treatment of natural teeth than opting for extraction and prosthetic replacement. Various treatment modalities have been suggested for multirooted teeth with advanced stage of periodontal disease of one of the roots. Hemisection and root resection is one of the treatment options for the subsistence of multirooted teeth which extend the functional life span of treated teeth. The main objective is to enhance professional and self-performed plaque control by converting multirooted teeth into non-furcated single-root teeth, thus, delaying the progression of attachment loss with resultant bone formation around the remaining roots.

More recently, when a deep periodontal defect of one of the roots or a periodontal-endodontic lesion is diagnosed, tooth extraction and replacement by a dental implant has unfortunately become the treatment of choice. However, the high prevalence of peri-implant complications and the failure rate of implants may rejuvenate the older concepts of periodontal resective surgery.

Once the tooth has been planned for resective treatment either vital or non-vital root resection of the periodontally involved root is done, followed by prosthetic treatment.

The other treatment option could be the regenerative approach making use of bone grafts and autologus platelet concentrates.

Periodontal regeneration requires a series of biological reactions that include-cell migration, cell adaptation, differentiation and proliferation, which is a multifactorial process in an orchestrated sequence. ${ }^{5}$ Platelets play an important role in wound healing of periodontal defects after treatment by the formation of thrombin and fibrin in addition to the release of growth factors and cytokines that would promote angiogenesis, inflammation and immune response leading to tissue repair. Thus, the use of platelet concentrates would help in acceleration of periodontal wound healing.

The success rate of predictive treatment modalities will increase if certain fundamental strategies are considered.

\section{CASE REPORT 1:}

A female patient aged 39 years reported with chief complaints of pain and loose teeth in the left lower back teeth region. On intra-oral evaluation the tooth was sensitive to percussion with grade II mobility, severe loss of attachment on the distobuccal and distolingual aspect of the tooth. On radiographic evaluation, deep vertical bone defect extending till apex of the distal root with furcation involvement was obvious. Patient was explained about the various treatment options for management. The most appropriate conservative treatment planned for the tooth was Hemisection after completion of endodontic therapy. Under local anaesthesia, a sulcular incision was given from the first premolar to the second molar and full-thickness flap was reflected. On reflection, a crater-like deep bony defect along the distal root was apparent. The defect was debrided using curettes to remove chronic inflammatory granulomatous tissue. The crown with the distal root was resected using vertical cut method. Vertical cut along the bifurcation was done using a carbide taper fissure bur. To corroborate separation and a smooth finished surface that would prevent plaque accumulation, a fine probe was used. The resected part was extracted, sterile saline was used to irrigate the socket and the flaps were coapted. Analgesics and antibiotics were advised. Intra-oral periapical radiograph showed retained mesial half of the crown and root. Sutures were removed after one week. After 1 month of healing of tissues, fixed dental prosthesis involving retained mesial half of the mandibular first molar, mandibular second molar and second premolar was given. IOPA at 9 months revealed adequate defect fill. (Figure 1a-1i)

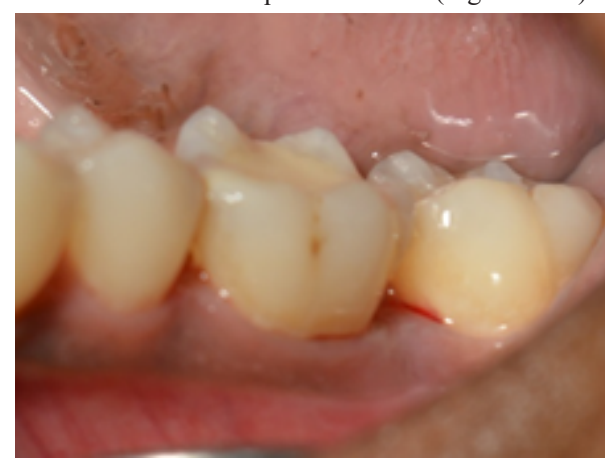

Figure 1 a: Pre-op clinical view

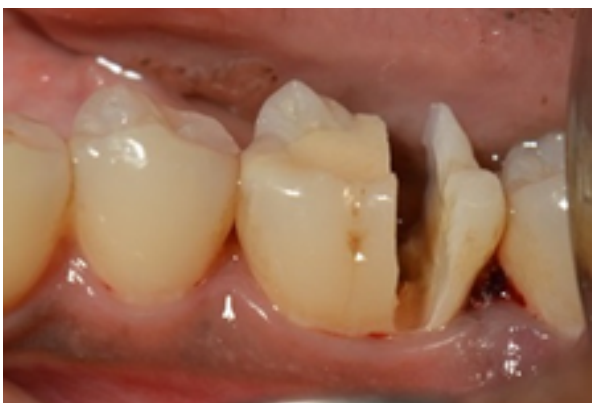

Figure 1 b: Clinical view showing line of resection with a vertical groove 


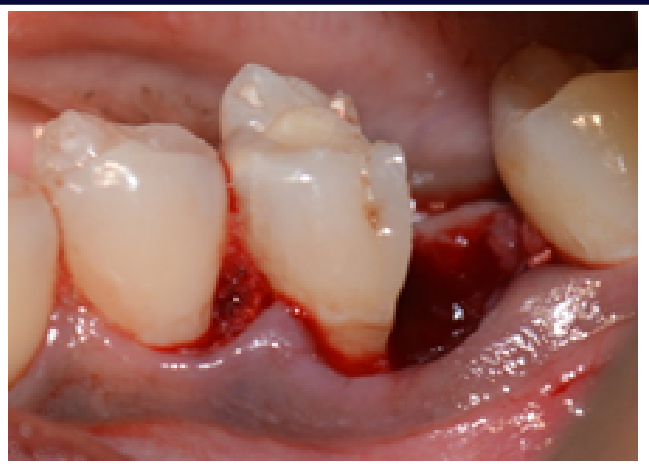

Figure $1 \mathrm{c}$ : Clinical view after removal of resected tooth

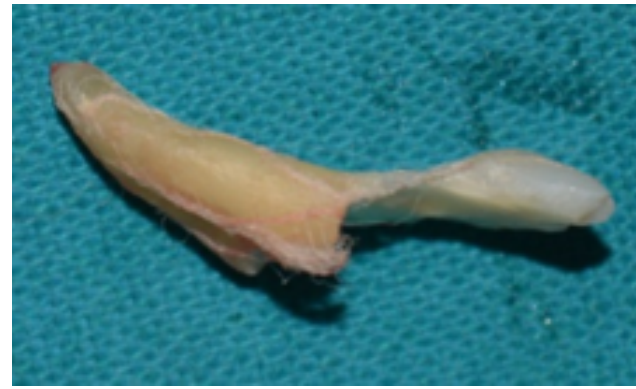

Figure $1 \mathrm{~d}$ : Resected part of tooth

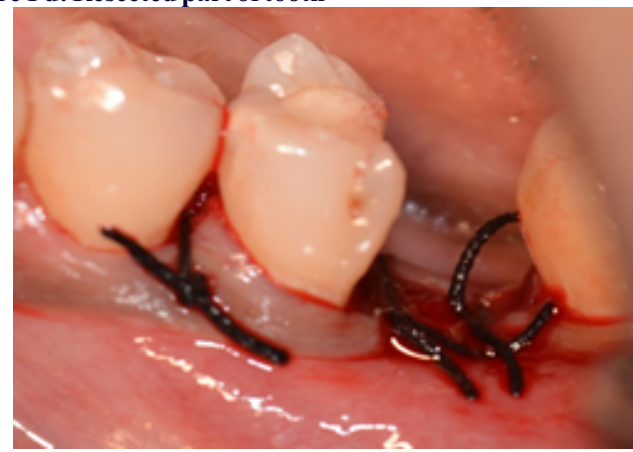

Figure 1 e: Sutures placed

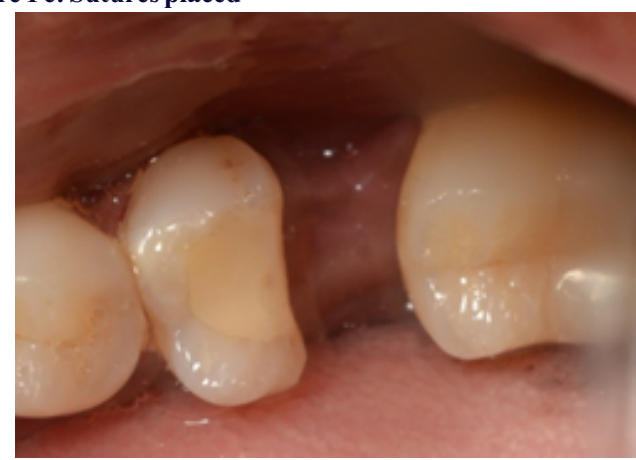

Figure 1 f: Healing after 1 month

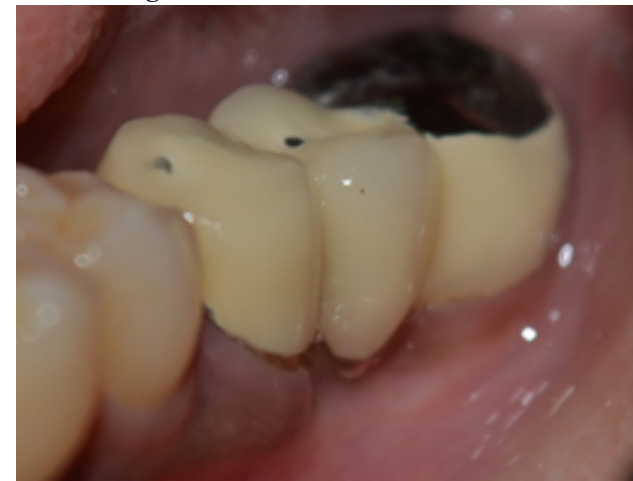

Figure $1 \mathrm{~g}$ : clinical view of 9 month follow-up

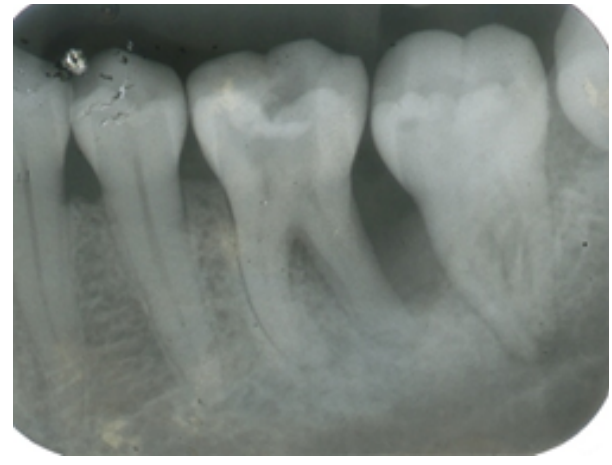

Figure $1 \mathrm{~h}$ : Periapical radiograph showing vertical defect extending till apical third of distal root.

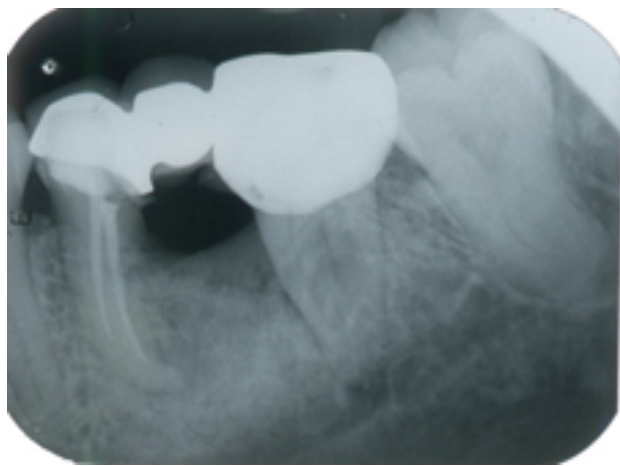

Figure 1 i: Periapical radiograph at 9-months showing defect fill till the junction of middle and cervical third.

\section{CASE REPORT 2:}

A 38 year old female patient reported with complaints of pain and loose teeth in the left upper back teeth region. Intra-oral examination showed generalized periodontal pockets and teeth mobility. On radiographic examination, OPG and periapical radiographs showed generalized horizontal bone loss and severe vertical bone loss with distobuccal root of maxillary left first molar with grade III furcation involvement. Since mesiobuccal and palatal roots showed adequate bone support it was decided to retain these roots and resect the distobuccal root. Complete medical history was taken and a written informed consent was obtained. Thorough phase I was performed and the soft tissue was assessed. Endodontic treatment was completed. $2 \%$ lidocaine was administered followed by a full thickness mucoperiosteal flap elevation. An oblique cut was made from the buccal furcation to the distobuccal furcation just apical to Cemento-enamel junction using a high speed tapered fissure carbide bur. A probe was run along the margins to corroborate smoothness of the resected area. The distobuccal resected root was extracted from the socket. Saline was used to irrigate the socket and the flaps were coapted using sutures. Post-operative instructions were given to avoid the use of operated side for 7 days, to have soft, lukewarm, semi-solid diet and to rinse with $0.2 \%$ chlorhexidine twice daily for 15 days. Patient was put on antibiotics and analgesics for 5 days. Sutures were removed after one week. Prosthesis was given after one month. The patient was periodically evaluated until 9 months. IOPA at 9 months revealed adequate defect fill. (Figure2a-2h)

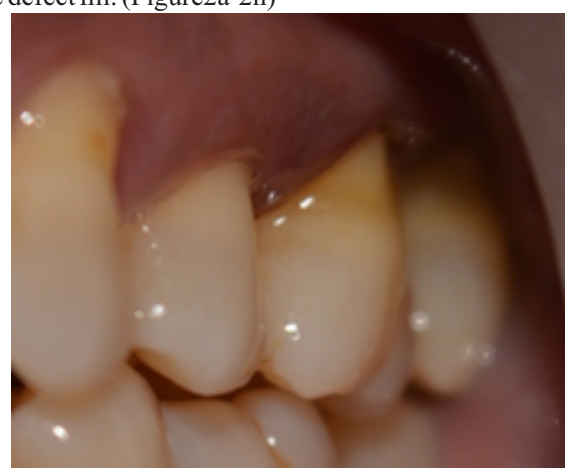

Figure 2 a: Pre-op clinical view 


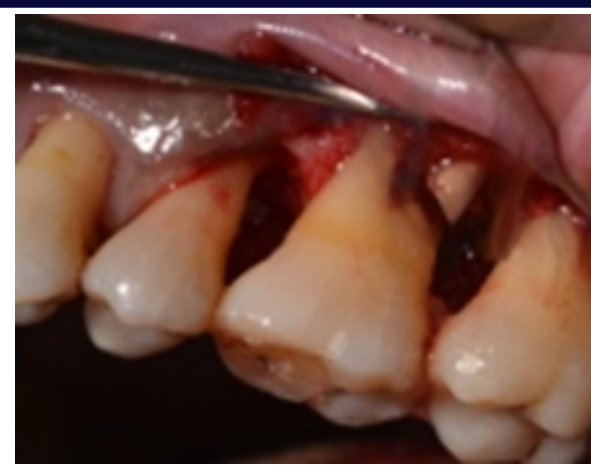

Figure $2 \mathrm{~b}$ : Clinical view showing line of resection extending till the furcation

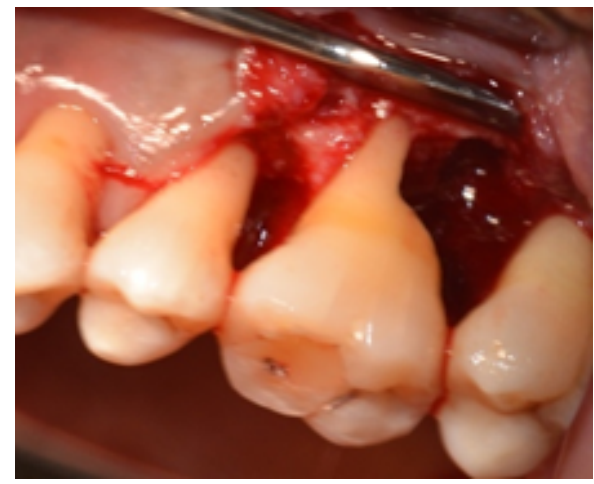

Figure 2 c: clinical view after removal of resected root

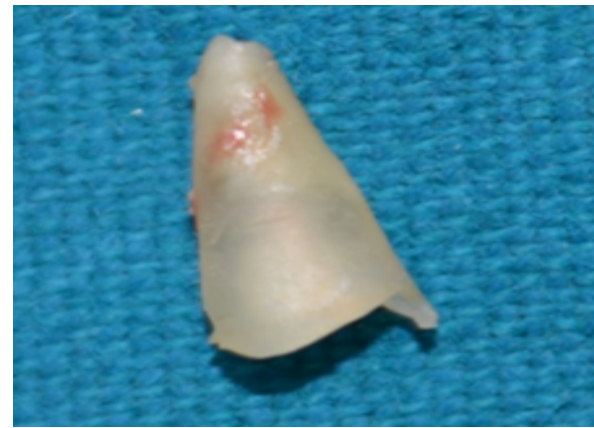

Figure 2 d: Resected root

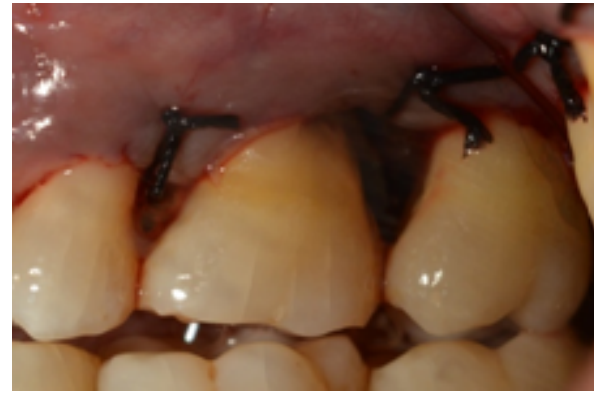

Figure 2 e: Sutures placed

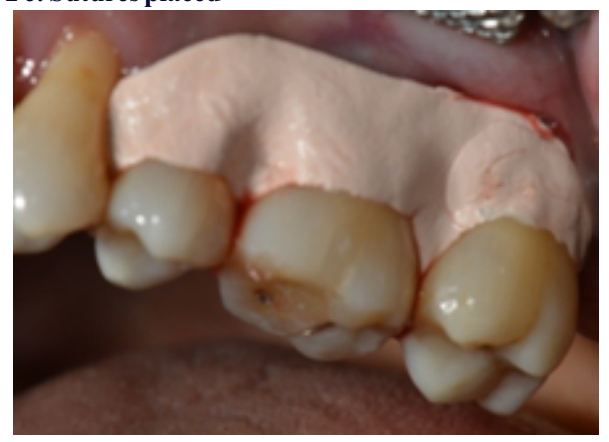

Figure 2 f: Periodontal pack placed

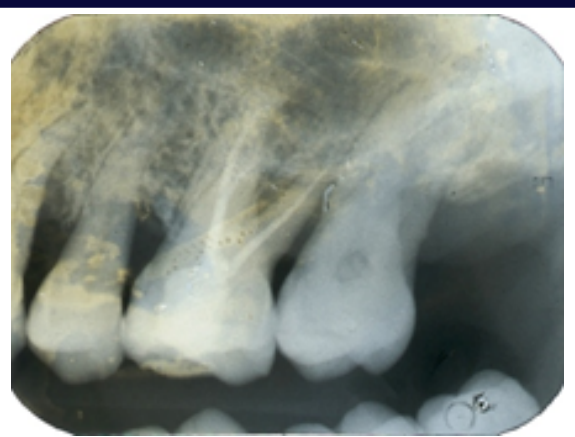

Figure 2 g: Periapical radiograph showing vertical defect extending till apical third of distobuccal root

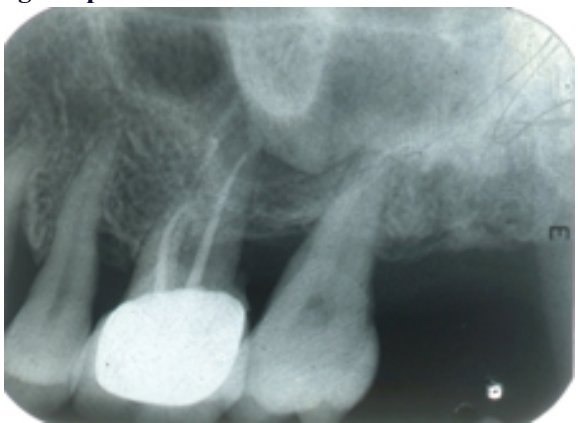

Figure 2 h: Periapical radiograph at 9 months showing defect fill till middle third of root

\section{CASE REPORT 3:}

A 38 year old female patient reported to the department of Periodontics, V.S. Dental college, Bengaluru with complaints of pain and loose teeth in the right lower back teeth region. On clinical examination there was severe loss of attachment on the distal root with grade II mobility. The radiographic examination revealed a deep infrabony defect on the distal surface of first molar. The patient was systemically healthy. Initial periodontal therapy consisted of scaling and root planing. Occlusal adjustment was performed by selective grinding. Following phase I therapy, clinical parameters were reevaluated. Local anaesthesia containing 2\% lignocaine was administered. With intra-crevicular incision, the full thickness mucoperiosteal incision was raised taking care to preserve the marginal and interdental tissues at the maximal possible level from first premolar to second molar. Thorough defect debridement with careful curettage of the inner surface of flap was done to remove subgingival calculus and granulation tissue. The surgical defect was then rinsed with copius amount of saline and the defect was classified as a combination defect, a 2-wall apically with distal and lingual walls present and one wall coronally with only lingual wall present. $10 \mathrm{ml}$ of patient's blood was drawn into a test tube and centrifuged immediately to obtain platelet rich fibrin, which was then squeezed carefully to form the PRF membrane. The defect was filled with Hydroxyapatite and $\beta$ TCP particles and packed into the defect to the level of the adjacent bony walls. After placement of the bone graft, the PRF membrane was placed and the flap was sutured using interrupted loop sutures. Periodontal dressing was placed for 7 days. The patient was asked not to use the operated side and to have soft, luke warm, semi-solid diet and use $0.2 \%$ chlorhexidine mouthwash twice daily for 15 days. The patient was put on analgesics and antibiotics for 5 days. Sutures were removed after 10 days. The patient was periodically evaluated until 1 year. IOPA at 1 year showed defect fill till the junction of middle and cervical third. (Figure 3a-3h)

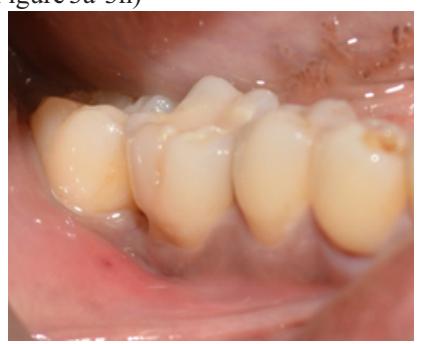

Figure 3 a: Pre-op clinical view 


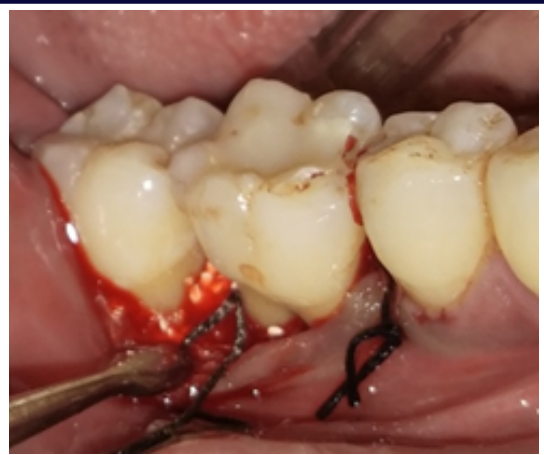

Figure 3 b: Clinical view showing placement of bone graft and PRF

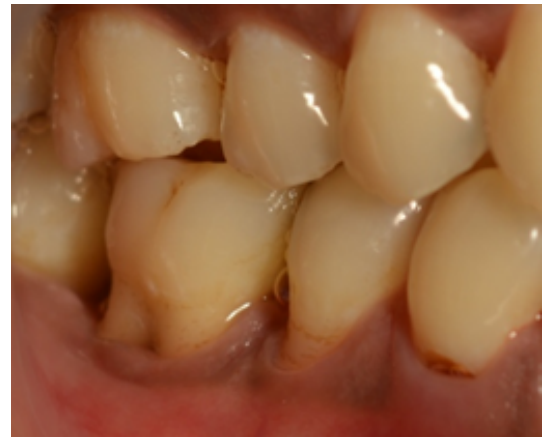

Figure 3 c: clinical view of 1 year follow-up

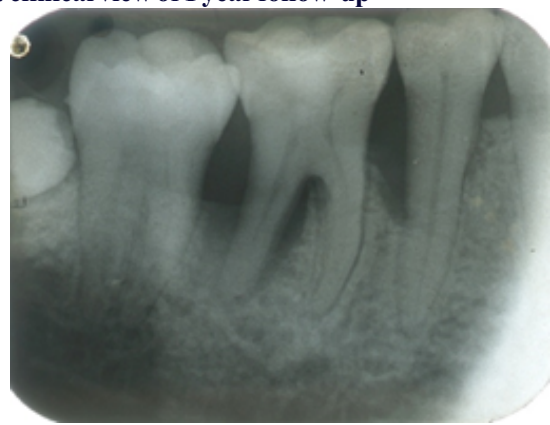

Figure 3 d: Periapical radiograph showing vertical defect extending till apical third of distal root

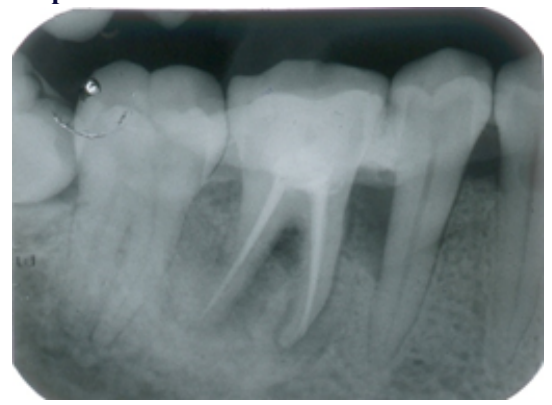

Figure 3 e: Periapical radiograph immediately after bone grafting

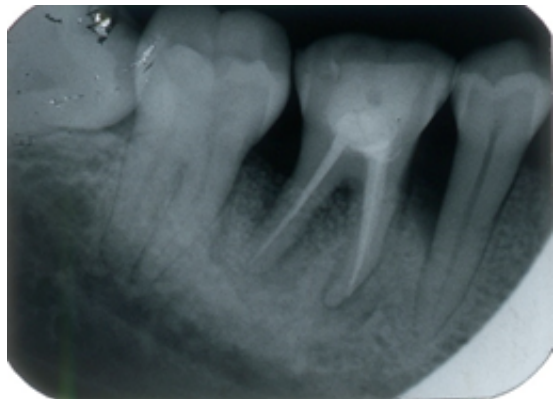

Figure 3 f: Periapical radiograph after 3 months showing defect fill till apical third

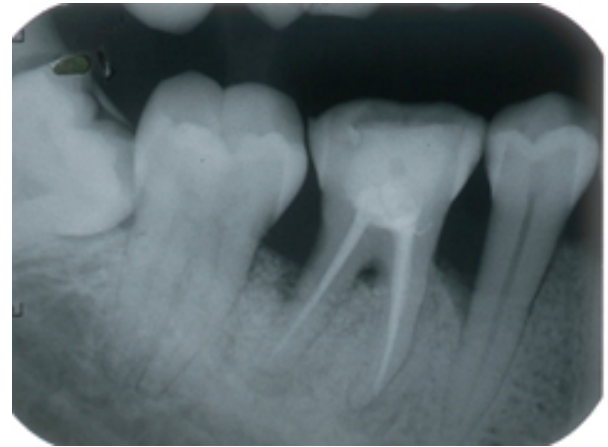

Figure 3 g: Periapical radiograph after 6 months showing defect fill till the junction of apical third and middle third of distal root.

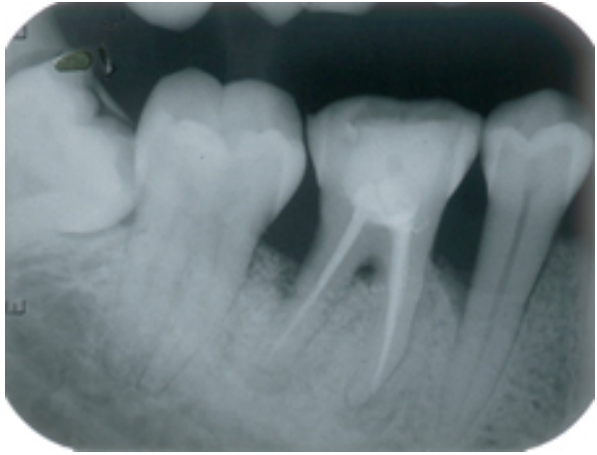

Figure 3 h: Periapical radiograph after 9 months showing defect fill till middle third of distal root.

\section{DISCUSSION:}

Treatment options for a periodontal disease involving one of the roots of multirooted teeth are limited. Success of hemisection and root resection procedures depend greatly on case selection criteria. ${ }^{8}$ It is salient to consider the following criteria before planing for resective procedures. ${ }^{3}$ (Table 1)

\section{Table 1: Criteria For Resective Procedures}

\begin{tabular}{|c|c|}
\hline 1. & $\begin{array}{l}\text { CASE SELECTION } \\
\text { No involvement of two proximal furcations } \\
\text { Tooth with large divergent roots and clinical crowns } \\
\text { Good amount of bone surrounding the residual root }(>50 \%) \\
\text { Lack of fusion between the roots } \\
\text { Good access possible for hygiene measures } \\
\text { Angulation and position of the tooth in the arch: a molar that is } \\
\text { buccally, lingually, mesially or distally tilted cannot be resected } \\
\text { Length and curvature of roots: long, straight roots are more } \\
\text { favourable for this process than short, conical roots } \\
\text { Favorable crown:root ratio } \\
\text { Strategic dental value of the retention } \\
\text { No mobility after equilibration } \\
\text { Pockets must be totally eliminated before selection } \\
\text { Isolated mandibular teeth should not be utilized for terminal } \\
\text { abutments for long span fixed bridges } \\
\text { Patient's factors: competent oral hygiene, medical status, costs } \\
\text { and time }\end{array}$ \\
\hline 2. & $\begin{array}{l}\text { ENDODONTIC PHASE } \\
\text { Access should be as small as possible } \\
\text { Excessive pressure should be avoided during preparation } \\
\text { Excessive preparation should be avoided } \\
\text { Excessive lateral condensation should be avoided: vertical } \\
\text { obturation is preferred }\end{array}$ \\
\hline 3. & $\begin{array}{l}\text { SURGICAL PHASE } \\
\text { Atraumatic separation and extraction of the candidate root } \\
\text { Bone recontouring is necessary: positive anatomy is needed } \\
\text { Root lips and irregular contour should be eliminated: positive } \\
\text { tooth morphology } \\
\text { Buccal and lingual } 1.5 \mathrm{~mm} \text { ferule effect is needed } \\
3.5 \mathrm{~mm} \text { available tooth structure between pulp chamber and } \\
\text { residual preparation is required: } 2 \mathrm{~mm} \text { for biological width and } \\
1.5 \mathrm{~mm} \text { for ferule effect } \\
\text { Socket preservation of the extraction socket of the root might be } \\
\text { done }\end{array}$ \\
\hline
\end{tabular}


4. RESTORATIVE PHASE

Use of a post should be limited: if necessary, prefabricated parallel-sided posts are preferred

Knife-edge finishing with metal margins are required

Smaller occlusal table size and smaller buccolingual width might be realized

Lateral forces should be reduced by making cuspal inclines les steep and eliminating balancing incline contacts

Molars are better restored as premolars

Under-contouring of the embrasure spaces

Crown margin should be precise and encompass the furcation

Crown contour should allow the patient easy access for cleaning "Sanitary pontic" might be the best design for cleaning

5. MAINTENANCE PHASE

Regular maintenance therapy every 4 months is necessary

Regular hygiene check and motivation

Regular occlusal check and meticulous adjustment of occlusion (often the patients should be using occlusal appliances to help reduce the forces placed on these teeth during parafunctions)

Effective anticaries measures

Hemisection is the splitting of a two-rooted tooth into two separate portions involving the crown. This process has been called bicuspidization or separation. ${ }^{9}$ In case 1 , hemisection eliminated the furcation area and the deep periodontal defect that would otherwise be difficult to maintain. Retaining the mesial root helped in bearing the occlusal load along with the abutment teeth.

Root resection is removal of one of the roots while retaining the remaining roots. Distobuccal root of maxillary root was resected in case 2 . The distobuccal root of first maxillary molars was the most affected. Its limited access during oral hygiene care and the thin vulnerable interdental septum being in close proximity to the mesiobuccal root of the second maxillary molar make it more easily compromised. ${ }^{10}$ The surface area of the palatal root and mesiobuccal root is more than the disobuccal root that would help sustain the occlusal load. The removal of distobuccal root eliminated the distobuccal furcation facilitating the maintenance of the most vulnerable area.

Periodontal healing is a complex process that involves organization of cells, biochemical triggers, and extracellular matrix synthesis for repair of the tissue. Role of platelets in hemostasis and wound healing is well established. ${ }^{12}$

Role of platelets in regeneration was proven way back in the 1970s, owing to the fact that it is a reservoir of growth factors that are responsible for neovascularization, collagen synthesis, cell division, cell differentiation, induction, and migration of other cells to the injured site.

The downgrowth of the junctional epithelium along the denuded root surface is one of the most important factors limiting the achievement of a predictable regeneration. ${ }^{14} \mathrm{PRF}$ was used as a GTR membrane in the present case for the prevention of such a migration. PRF promotes the expression of phosphorylated extracellular signal-regulated protein kinase (p-ERK) and stimulates the production of osteoprotegerin which helps in proliferation of osteoblasts. ${ }^{15}$ It also releases various growth factors like PDGF-AA, PDGF-AB, PDGF-BB, PDGF-B1, VEGF, EGF and IGF, all of which promote periodontal regeneration. ${ }^{16}$

Dental implants were first utilized solely to replace missing or hopeless teeth. However, currently teeth that are endodontically, periodontally involved with fair prognosis are being removed citing that implant procedures are more predictable when compared to other treatment modalities. ${ }^{17}$ Moreover, implants are not free of complications. A recent consensus conference based systematic review revealed an overall 5-year single implant survival rate of $96.6 \%$, technical complications of $11.8 \%$ and biologic complications of $6.4 \% .^{18}$ In comparison, another study with root resection and hemisection of hopeless teeth showed a similar overall survival rate of 5-40 years. ${ }^{8}$ Therefore, it is obvious that teeth with advanced periodontal disease can be treated safely and successfully with resective / regenerative procedures. All the three cases responded favourably to treatment with considerable reduction in mobility, were functional and stable upto 9 months follow-up.

\section{CONCLUSION:}

Hemisection, root resection and use of hydroxyapatite bone graft plus
$\beta$-TCP with PRF has acquired affirmation as a conservative treatment option and teeth so attended have fulfilled the appeals of function. A dentist should discuss various treatment options and their prognosis with the patients during consideration of treatment options so that the patient can choose best and conservative treatment available.

\section{ACKNOWLEDGMENTS:}

We would like to acknowledge Dr. Ranjitha G. R. and Dr. Shreya Harti Post-graduates, Department of conservative dentistry and endodontics and Dr. Fahadah Ubaid, Post-graduate, Department of Prosthodontics and Implantology, V S Dental College, Bangalore.

Conflicts of interest: There are no conflicts of interest.

Declaration of patient consent: The authors certify that we have obtained all appropriate patient consent forms. In the form the patients have given their consent for their images and other clinical information to be reported in the journal. The patients understand that their names and initials will not be published and due efforts will be made to conceal their identity, but anonymity cannot be guaranteed.

Financial support and sponsorship: Nil

\section{REFERENCES:}

1. Megarbane JM, Kassir AR, Mokbel N, Naaman N. Root Resection and Hemisection Revisited. Part II: A Retrospective Analysis of 195 Treated Patients with Up to 40 Years of Follow-up. International Journal of Periodontics \& Restorative Dentistry. 2018 Nov $1 ; 38(6)$

2. Jayachandran Prathapachandran NS. Management of peri-implantitis. Dental research journal.2012 Sep;9(5):516.

3. Mokbel N, Kassir AR, Naaman N, Megarbane JM. Root Resection and Hemisection Revisited. Part I: A Systematic Review. International Journal of Periodontics \& Restorative Dentistry. 2019 Jan 1:39(1).

4. Preeja C, Arun S. Platelet-rich fibrin: Its role in periodontal regeneration. The Saud Journal for Dental Research. 2014 Jul 1;5(2):117-22

5. Chen FM, Jin Y. Periodontal tissue engineering and regeneration: current approache and expanding opportunities. Tissue Engineering Part B: Reviews. 2010 Jan $11 ; 16(2): 219-55$

6. Preeja C, Arun S. Platelet-rich fibrin: Its role in periodontal regeneration. The Saudi Journal for Dental Research. 2014 Jul 1;5(2):117-22.

7. Del Fabbro M, Bortolin M, Taschieri S, Weinstein R. Is platelet concentrate advantageous for the surgical treatment of periodontal diseases? A systematic review and meta-analysis. Journal of Periodontology. 2011 Aug 1;82(8):1100-11.

8. Megarbane JM, Kassir AR, Mokbel N, Naaman N. Root Resection and Hemisection Revisited. Part II: A Retrospective Analysis of 195 Treated Patients with Up to 40 Year of Follow-up. International Journal of Periodontics \& Restorative Dentistry. 2018 Nov $1 ; 38(6)$

9. Newman M, Takei H, Klokkevold P. Carranza's Clinical Periodontology 11 th edition St Louis: Mosby. 2012:903.

10. Walter C, Weiger R, Zitzmann NU. Periodontal surgery in furcation-involved maxillary molars revisited - an introduction of guidelines for comprehensive treatment. Clinical oral investigations. $2011 \mathrm{Feb} 1 ; 15(1): 9-20$

11. SarafAA, Patil AC. Hemisection. World J Dent 2013;4(3):180-187.

12. Gassling VL, Acil Y, Springer IN, Hubert N, Wiltfang J. Platelet-rich plasma and pal Endod. 2009;108:48-55

13. Kiran NK, Mukunda KS, Tilak Raj TN Platelet concentrates: A promising innovation in dentistry. J Dent Sci Res. 2011;2:50-61

14. Egelberg J. Regeneration and repair of periodontal tissues. J Periodontal Res 1987;22:233-242

15. Chang IC, Tsai CH, Chang YC. Platelet-rich fibrin modulates the expression of extracellular signal-regulated protein kinase and osteoprotegerin in human osteoblasts. J Biomed Mater Res A 2010;95:327-32

16. Su CY, Kuo YP, Tseng YH, Su CH, Burnouf T. In vitro release of growth factors from platelet-rich fibrin (PRF): a proposal to optimize the clinical applications of PRF Ora Surgery, Oral Medicine, Oral Pathology, Oral Radiology, and Endodontology $2009 \mathrm{Ju}$ 1;108(1):56-61.

17. Kar, Kian \& Frydman, Alon \& Simonian, Krikor. (2013). Dental Implants: replacemen of missing teeth or to replace teeth? Journal de Periodontologie \& d'Implantologie Orale. 32.55-69

18. Zembic A, Kim S, Zwahlen M, Kelly JR. Systematic review of the survival rate and incidence of biologic, technical, and esthetic complications of single implant abutment supporting fixed prostheses. International journal of oral \& maxillofacial implants. 201 Jan $2 ; 29$ 